\title{
Recombinant HE4 protein promotes proliferation of pancreatic and endometrial cancer cell lines
}

\author{
QINSHENG LU ${ }^{1,2^{*}}$, HAIBIN CHEN $^{1 *}$, CHRISTOPHER SENKOWSKI $^{3}$, JIANHAO WANG $^{4}$, XUE WANG $^{2}$, \\ STEVEN BROWER ${ }^{5}$, WAYNE GLASGOW ${ }^{2}$, DAVID BYCK ${ }^{7}$, SHI-WEN JIANG ${ }^{2,6,7}$ and JINPING LI ${ }^{2,4,7}$ \\ ${ }^{1}$ Department of Histology and Embryology, Shantou University Medical College, Shantou, Guangdong 515041, P.R. China; \\ ${ }^{2}$ Department of Biomedical Science, Mercer University School of Medicine; ${ }^{3}$ Curtis and Elizabeth Anderson \\ Cancer Institute, Department of Surgery, Memorial Health University Medical Center, Savannah, GA 31404, USA; \\ ${ }^{4}$ School of Pharmaceutical Engineering and Life Science, Changzhou University, Changzhou, Jiangsu 213164, P.R. China; \\ ${ }^{5}$ Department of Surgery and Surgical Oncology, Beth Israel Medical Center, New York, NY 10003, USA; \\ ${ }^{6}$ Department of Obstetrics and Gynecology, The Second Affiliated Hospital of Wenzhou Medical University, \\ Wenzhou, Zhejiang 325027, P.R. China; ${ }^{7}$ Department of Obstetrics and Gynecology, \\ Memorial Health University Medical Center, Savannah, GA 31404, USA
}

Received July 28, 2015; Accepted September 4, 2015

DOI: $10.3892 /$ or.2015.4339

\begin{abstract}
Pancreatic adenocarcinoma is one of the most deadly malignancies, and endometrial cancer represents the most common gynecologic cancer in the USA. Better understanding on the pathologic mechanisms and pathways is required for effective treatment of these malignancies. Recently, human epididymis protein 4 (HE4 or WFDC2), a secretory glycoprotein, was found to be overexpressed in pancreatic and endometrial cancers. In addition, studies have shown that HE4 overexpression in endometrial cancer cell lines led to faster cancer progression in a mouse subcutaneous model. These findings raise a question on the role(s) of secretory, extracellular HE4 in cancer development. In the present study, we found that treatment of pancreatic and endometrial cancer cell lines with purified, extracellular HE4 protein led to a significant increase in cell viability and proliferation. Moreover, extracellular HE4 protein was able to increase DNA synthesis, and modulate the mRNA and protein levels of cell cycle marker PCNA and cell cycle inhibitor p21. These effects appeared to be robust and sustainable and required a relatively low concentration of HE4 protein. The findings indicated the secreted, extracellular HE4 may carry some physiopathological functions. Via paracrine/endocrine actions, circulatory
\end{abstract}

Correspondence to: Professor Shi-Wen Jiang or Jinping Li, Department of Biomedical Science, Mercer University School of Medicine, 4700 Waters Avenue, Savannah, GA 31404, USA

E-mail: jiang_s@mercer.edu

E-mail: 1i_j@mercer.edu

*Contributed equally

Key words: human epididymis protein 4, cell proliferation, cell cycle, pancreatic cancer, endometrial cancer
HE4 produced by malignant cells may contribute to pancreatic and endometrial cancer progression and/or metastasis.

\section{Introduction}

Pancreatic cancer ranks the fourth most common cause of cancer-related deaths in the USA (1). In 2014, there were 46,420 estimated new pancreatic cancer cases and 39,590 estimated deaths in the USA (1). Pancreatic cancer accounts for $3.5 \%$ of estimated new cancer deaths worldwide, and its 5 -year overall survival rate is below $6 \%(2,3)$. Multiple genetic and epigenetic alterations have been identified in pancreatic cancer (4-7), but the exact molecular mechanisms are poorly defined for this aggressive malignancy. Endometrial carcinoma (EC) is the most common gynecologic malignancy in the USA. It is estimated that in 2014, there were 52,630 new endometrial cancer cases and 8,590 EC-caused deaths in the USA, which accounts for $6 \%$ of incidence and $3 \%$ of deaths for women's cancers (1). Although the etiologies including the effects of genetic, epigenetic and hormonal factors for the development of EC have been well documented, many cellular events and pathways contributing to EC progression remain to be elucidated.

The HE4 gene was first cloned in 1991 from the human epididymis by Kirchhoff et al (8). Structural analysis indicated that HE4 is a whey-acidic-protein (WAP) family member containing two WAP-type four-disulphide core (WFDC) domains $(9,10)$. HE4 gene is located to chromosome 20q12-13.1, a region harboring 14 homologous genes (9), including secretory leukocyte proteinase inhibitor (SLPI; or anti-leukoproteinase 1) and elafin, the two better characterized WAP domain proteins. HE4 expression has been detected in some normal tissues and a variety of malignant tissues. Low levels of HE4 expression were observed in the epithelium of female genital track (endocervical and endometrial glands, and fallopian tube), breast, prostate gland, distal convoluted tubules 
of the kidney, bronchial epithelium, salivary glands, anterior pituitary and lacrimal gland $(11,12)$. While normal pancreas was generally negative in immunostaining using HE4 antibodies $(13,14)$, recent studies indicated that HE4 expression is present in many pancreatic carcinomas $(14,15)$. High levels of HE4 expression are found in ovarian serous carcinomas, and moderate levels in adenocarcinomas of the lung and pancreatic carcinomas, and endometrial cancers (11,14-16). Since HE4 is secreted to the circulation (13), the increased serum HE4 levels have been extensively evaluated as a biomarker for the diagnosis of ovarian and endometrial cancers (17-19). Various studies have shown that the serum HE4 is detectable and increased compared to healthy controls in pancreatic adenocarcinoma patients $(15,19,20)$.

WAP domain family proteins have been found to carry out multiple functions including protease inhibitory, antimicrobial and anti-inflammatory activities $(21,22)$. Recently, the protease inhibitor activity of HE4 was confirmed by experiments showing that HE4 inhibits serine proteases, aspartyl and cysteine proteases, and matrix metalloproteinases (23-25). Though HE4 is upregulated in many malignancies, there is a limited knowledge on the function of HE4 in cancer development. In endometrial cancers, higher HE4 levels positively correlate with more aggressive phenotype, larger tumor size and myometrial invasion $(26,27)$, and negatively correlate with the overall survival, disease-free survival and progression-free survival $(12,26,28,29)$. Using endometrial cancer cell lines and mouse ectopic subcutaneous cancer models, this and other groups have shown that overexpression of HE4 led to increased cell proliferation and faster cancer progression. In ovarian cancer and EC, HE4 was found to promote cancer cell growth in vitro (30-32). HE4-induced anti-apoptosis and drug resistance in ovarian cancer cell lines have also been reported $(33,34)$. It is noteworthy that previous data in endometrial cancer cells were obtained from overexpression or knockdown experiments, whereas the function of secreted, circulatory HE4 is unclear. Moreover, HE4 activities in pancreatic cancer cells have not been reported.

In the present study, we investigated whether the recombinant, extracellular HE4 protein purified from human cells could affect the growth of pancreatic cancer and EC cells. These experiments explore the potential role(s) of extracellular HE4 for pancreatic and endometrial cancer progression through paracrine/endocrine actions.

\section{Materials and methods}

Cell culture and treatment. Human endometrial cancer cell line KLE was obtained from the American Type Culture Collection (ATCC). The pancreatic cancer cell line Suit-2 was a gift from Dr Kaustubh Datta, University of Nebraska). Cells were grown in Dulbecco's modified Eagle's medium (DMEM)/F12 medium (HyClone Laboratories, Inc., Logan, UT, USA) supplemented with $10 \%$ fetal bovine serum and $1 \%$ penicillin/streptomycin (100X; Mediatech, Inc., Manassas, VA, USA). Cell culture was maintained at $37^{\circ} \mathrm{C}$ and a $5 \% \mathrm{CO}_{2}$ atmosphere. Recombinant HE4 protein was expressed and isolated from human HEK 293 cells (cat. no. 12609-H08H; Sino Biological Inc., Beijing, China) and applied for cell treatment as described in each specific experiment.
MTS cell viability assay. Suit-2 and KLE cells were seeded

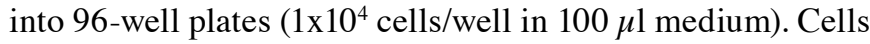
were treated with $10 \mathrm{nM}$ of recombinant $\mathrm{HE} 4$ protein for 1 to 5 days. Cells without HE4 treatment were used as controls at each time point. At $1 \mathrm{~h}$ before each time point, $20 \mu \mathrm{l}$ CellTiter 96 AQueous One Solution Reagent (cat. no. G3581; Promega, Madison, WI, USA) was added, and the absorbance at $490 \mathrm{nM}$ was measured on a 96-well plate reader (Modulus Microplate Multimode Reader; Turner BioSystems, Inc., USA). The assay was performed in triplicate and the background absorbance in wells without cells was used as blank control.

Cell counting. Suit-2 and KLE cells were seeded into 12-well plates $\left(8 \times 10^{4}\right.$ cells/well). Cells were treated with recombinant HE4 protein (10 $\mathrm{nM}$, final concentration) for 1 to 6 days and every $24 \mathrm{~h}$ cell numbers were counted. At each time point, cells were detached and dispersed by digestion with 1X trypsinEDTA. After mixing with $0.4 \%$ trypan blue solution, cells were counted with a haemocytometer under a microscope. The assay was performed in triplicates and data were presented as mean $\pm \mathrm{SD}$.

BrdU incorporation assay. Suit-2 and KLE cells were seeded on two-chamber slides ( $1 \times 10^{5}$ cells/well) and cultured under standard conditions. Following treatment with recombinant HE4 protein (10 nM, final concentration) for $48 \mathrm{~h}$, 5-bromo-2'-deoxyuridine (BrdU) (cat. no. 000103; Invitrogen, Rockville, MD, USA) was added into the cultures to label the $\mathrm{S}$-phase cells for $2 \mathrm{~h}$. Following BrdU labeling, cells were washed with cold phosphate-buffered saline (PBS), fixed in $70 \%$ alcohol at $4^{\circ} \mathrm{C}$ for $30 \mathrm{~min}$ and permeabilized in $0.3 \%$ Triton X-100 for $30 \mathrm{~min}$. BrdU immunocytochemical staining was performed using the BrdU staining kit (cat. no. 933943; Invitrogen) following the manufacturer's instructions. Images were captured by Nikon DS-Fi2 camera (Nikon Instruments, Inc., Melville, NY, USA). The BrdU-positive cells were counted and BrdU incorporation rates were calculated. The assay was repeated three times and final results were presented as mean $\pm \mathrm{SD}$.

RNA extraction and real-time PCR. Cultured cells were washed twice with cold PBS. Total RNA was extracted with RNeasy plus mini kit (cat. no. 74136; Qiagen, Valencia, CA, USA). RNA concentration was measured with the use of NanoDrop 1000 spectrophotometer(Thermo Fisher Scientific, Wilmington, DE, USA). One microgram of total RNA was used for cDNA synthesis with High Capacity RNA-to-cDNA kit (cat. no. 4387406; Applied Biosystems, Foster, CA, USA) in $20 \mu \mathrm{l}$ reactions. cDNA was diluted to $100 \mu \mathrm{l}$ with nucleasefree water. Real-time PCR was conducted in $12 \mu 1$ reactions containing $2 \mu \mathrm{l}$ of diluted cDNA, $6 \mu \mathrm{l}$ of real-time PCR reaction mixture (cat. no. 75600; VeriQuest SYBR-Green real-time PCR master mix with ROX; Affymetrix, Cleveland, $\mathrm{OH}, \mathrm{USA}), 1 \mu \mathrm{l}$ of $10 \mu \mathrm{M}$ forward primer, $1 \mu \mathrm{l}$ of $10 \mu \mathrm{M}$ backward primer and $2 \mu \mathrm{l}$ of nuclease-free water. Real-time PCR primers were designed using Primer3 software (Table I). Reactions were carried out under the following conditions: initial denaturation at $95^{\circ} \mathrm{C}$ for $10 \mathrm{~min}$, followed by 40 cycles of denaturation at $95^{\circ} \mathrm{C}$ for $15 \mathrm{sec}$, annealing and extension at 
Table I. The real-time PCR primers.

\begin{tabular}{llllc}
\hline NCBI accession no. & Gene & Direction & \multicolumn{1}{c}{ Primer sequence } & Product size (bp) \\
\hline NM_002592.2 & PCNA & Forward & 5'-TGTCCAAAATACTAAAATGCGCCG-3' & 82 \\
& & Reverse & 5'-ACTAGCGCCAAGGTATCCGC-3' & 127 \\
NM_000389.4 & p21 & Forward & 5'-GCAGACCAGCATGACAGATTTC-3' & 71 \\
& & Reverse & 5'-ATGTAGAGCGGGCCTTTGAG-3' & 71 \\
NM_002046.5 & GAPDH & Forward & 5'-ACCATCTTCCAGGAGCGAGA-3' & \\
& & Reverse & 5'-GACTCCACGACGTACTCAGC-3' & \\
\hline
\end{tabular}

$60^{\circ} \mathrm{C}$ for $1 \mathrm{~min}$, using the ABI 7900HT fast Real-Time PCR system (Applied Biosystems). PCR products were resolved in $1.8 \%$ TAE agarose/ethidium bromide gels and the single band pattern with predicted size of PCR product indicated specific amplification. GAPDH was used as the internal reference gene. Results were standardized by those from GAPDH. Relative changes in mRNA expression were calculated using the $2^{-\Delta \Delta \mathrm{Ct}}$ method (35) and presented as mean \pm SD.

Western blot analysis. Cultured cells were washed twice with cold PBS ( $\mathrm{pH} 7.4$ ) and lysed on ice in cold lysis buffer [150 mM NaCl, $50 \mathrm{mM}$ Tris- $\mathrm{HCl}$ (pH 7.4), 0.1\% SDS, $0.5 \%$ sodium deoxycholate, $1 \%$ Nonidet P-40] supplemented with $1 \%$ Halt protease inhibitor coktail (100X; Thermo Scientific, Rockford, IL, USA), $1 \mathrm{mM}$ of phenylmethylsulfonyl fluoride (PMSF), $5 \mathrm{mM}$ of sodium fluoride $(\mathrm{NaF})$ and $1 \mathrm{mM}$ of sodium vanadate $\left(\mathrm{Na}_{3} \mathrm{VO}_{4}\right)$. Cell suspensions were kept on ice for $30 \mathrm{~min}$ before centrifugation at $18,400 \mathrm{x}$ g at $4^{\circ} \mathrm{C}$ for $30 \mathrm{~min}$. The supernatants were collected and stored at $-80^{\circ} \mathrm{C}$ until use. Forty micrograms of proteins was mixed with SDS-loading buffer, boiled for $5 \mathrm{~min}$, separated in 12 or $15 \%$ SDS-polyacrylamide gels, and transferred onto PVDF membranes. Non-specific reaction was blocked for $2 \mathrm{~h}$ at room temperature in TBS containing 5\% non-fat milk and $0.1 \%$ Tween-20. Primary antibodies (cat. no. SAB4502103, rabbit polyclonal anti-PCNA antibody, 1:1,000; Sigma-Aldrich, St. Louis, MO, USA; cat. no. sc-6246, mouse monoclonal antip21 antibody, 1:200; Santa Cruz Biotechnology, Santa Cruz, CA, USA) diluted in blocking solution were applied and incubation was carried out at room temperature for $2 \mathrm{~h}$. Secondary antibodies (cat. no. sc-2301, goat anti-rabbit IgG-HRP; cat. no. sc-2302, goat anti-mouse IgG-HRP; both from Santa Cruz Biotechnology) were 1:6,000 diluted and incubation were performed at room temperature for $40 \mathrm{~min}$. The blots were developed with ECL system (Thermo Scientific) and exposed to X-ray film. Membranes were stripped and $\beta$-actin was detected with anti- $\beta$-actin mouse monoclonal antibody (cat. no. A5316, 1:6,000; Sigma-Aldrich). Results of $\beta$-actin detection served as protein loading controls.

Statistical analysis. Averages and standard deviations were calculated for each experimental group. Student's t-tests were performed using SPSS 17.0 software (SPSS, Inc., Chicago, IL, USA) and $\mathrm{P} \leq 0.05$ was considered the level for statistical significance.

\section{Results}

Recombinant HE4 protein promotes pancreatic and endometrial cancer cell viability. Native HE4 is known to be a glycosylated and secretory protein. In order to explore the function of extracellular HE4, we used the glycosylated form of HE4 protein produced in human HEK 293 cells (34) to treat pancreatic and endometrial cancer cells. It was found that following the treatment with relatively low concentration of recombinant $\mathrm{HE} 4$ protein $(10 \mathrm{nM})$, both pancreatic cancer and endometrial cancer cell lines displayed a significantly increased cell viability when compared to the control group without HE4 treatment (Fig. 1). This stimulation appeared to be rapid, being detectable after one (Suit-2 cells) or two days (KLE cells) of treatment, and sustainable throughout the time points thereafter. Thus, extracellular HE4 has a robust effect on the viability of both pancreatic and endometrial cancer cell lines.

Recombinant HE4 promotes pancreatic cancer and endometrial cancer cell growth. Since MTS experiment measures total cell vitality rather than assessing cell growth, we performed cell counting assay to determine the effect of extracellular HE4 on cell proliferation. Following treatment with $10 \mathrm{nM}$ of recombinant HE4 for three days, pancreatic cancer Suit- 2 cells grew significantly more rapidly than the control group without HE4 treatment (Fig. 2A). The same activity of recombinant HE4 protein was observed in endometrial cancer KLE cells (Fig. 2B). Consistent with the stimulatory effect on cell viability, HE4-mediated promotion of cell growth lasted throughout the time points observed.

HE4 treatment increases DNA synthesis in pancreatic and endometrial cancer cells. To investigate whether the recombinant HE4 protein affects DNA synthesis, we compared the BrdU incorporation rates between cells with or without HE4 treatment. As shown in Fig. 3, treatment with HE4 protein for $48 \mathrm{~h}$ increased BrdU incorporation-positive Suit-2 cells from 35.6 to $52.3 \%(\mathrm{P}<0.01)$ (Fig. 3B). For endometrial cancer KLE cells, BrdU incorporation-positive cells were increased from 37.6 to $46.9 \%(\mathrm{P}<0.01)$ following the treatment with recombinant $\mathrm{HE} 4$ protein (Fig. 3C). These results demonstrated that extracellular HE4 protein can stimulate DNA synthesis in both pancreatic and endometrial cancer cell lines. 

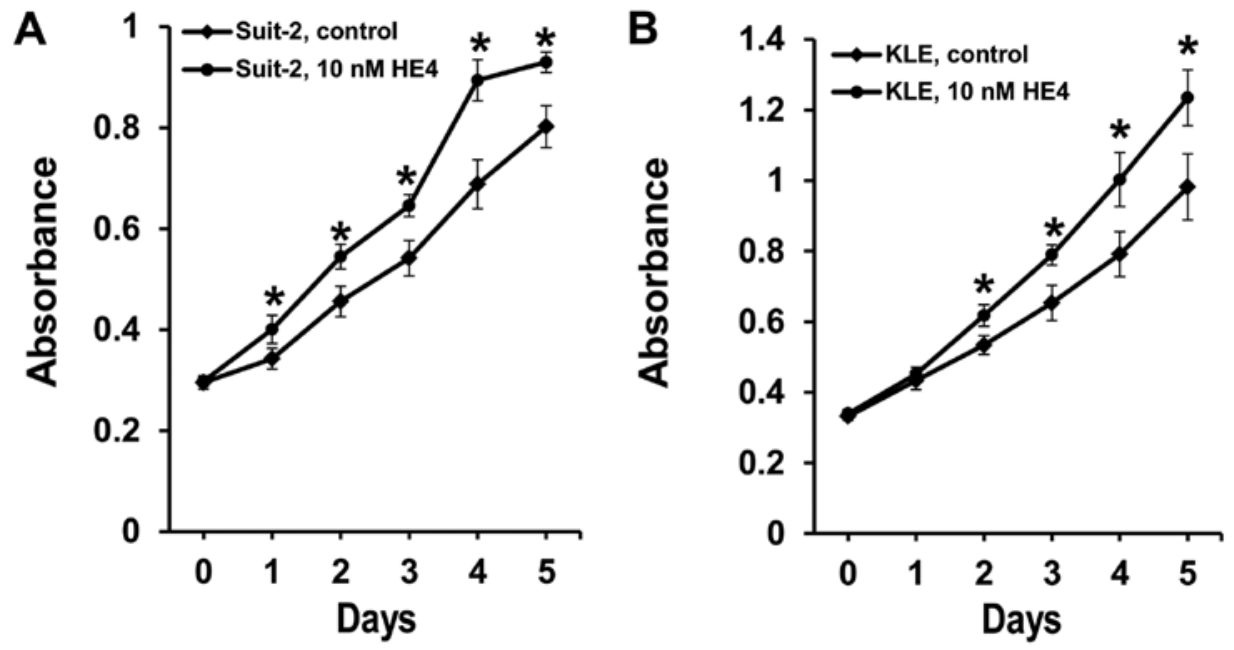

Figure 1. Recombinant HE4 protein promotes pancreatic cancer and endometrial cancer cell viability. For HE4 protein treatment, $10 \mathrm{nM}$ of HE4 or the same volume of PBS (control) was added to the culture medium. Media with or without HE4 were replaced every $24 \mathrm{~h}$. MTS assay was performed and absorbance at $490 \mathrm{nM}$ was recorded. Experiments were performed three times independently in triplicates. (A) Pancreatic cancer Suit-2 cells. (B) Endometrial cancer KLE cells. Data are shown as mean \pm SD. Student's t-test was performed. $\mathrm{P} \leq 0.05$.

A

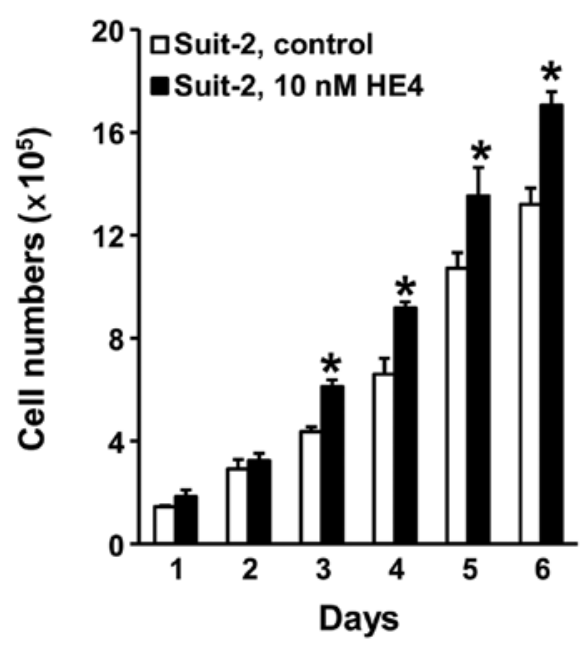

B

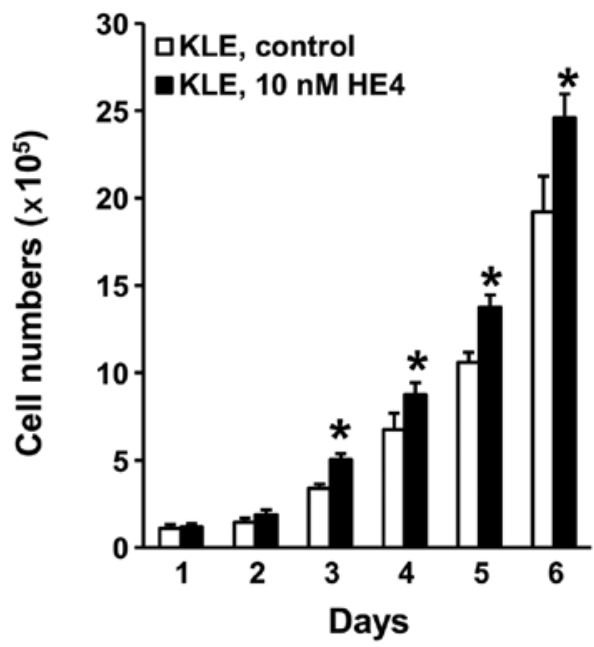

Figure 2. Recombinant HE4 protein promotes pancreatic cancer and endometrial cancer cell proliferation. Pancreatic cancer Suit-2 and endometrial cancer KLE cells were treated with recombinant HE4 $(10 \mathrm{nM})$ for 6 days. The same volume of PBS was added to the culture in control groups. Culture media were replaced every $24 \mathrm{~h}$. Cells were counted with the use of haemocytometer under a microscope every day for 6 days consecutively. (A) Pancreatic cancer Suit-2 cells. (B) Endometrial cancer KLE cells. Data are shown as mean \pm SD. Student's t-test was performed. "P $\leq 0.05$.

HE4 regulates PCNA and 21 gene expression in pancreatic and endometrial cancer cells. PCNA is a key molecule for DNA synthesis and its expression levels are considered an important marker for cell division. p21 is a critical cell cycle regulator and its deregulation is required for G1-S transition. We examined how the recombinant HE4 protein treatment may affect the expression of cell cycle marker/regulator. As shown in Fig. 4A, results of real-time PCR show that treatment with $10 \mathrm{nM}$ recombinant HE4 protein for $24 \mathrm{~h}$ upregulated PCNA, but downregulated cell cycle inhibitor p21, mRNA levels, in both Suit-2 and KLE cell lines. On the protein level, results of western blotting indicated that following $48 \mathrm{~h}$ of treatment with $10 \mathrm{nM} \mathrm{HE} 4$, PCNA and p21 expression underwent changes in the same directions as observed on mRNA levels (Fig. 4B). Treatment with $20 \mathrm{nM}$ of HE4 led to stronger effects in both cell lines. These results indicated that recombinant $\mathrm{HE} 4$ protein may promote pancreatic and endometrial cancer cell proliferation via regulating the expression of cell cycle regulators.

\section{Discussion}

Pancreatic ductal adenocarcinoma, accounting for more than $90 \%$ of pancreatic tumors, is one of the most deadly malignancies (4). Most patients are diagnosed at advanced, unresectable stage at which currently available treatment procedures have only limited effects (36). Poor understanding on the pathologic mechanisms impede the development of new treatment modalities. Applying the large-scale serial analysis of gene expression (SAGE) technique, Missiaglia et al observed that HE4 mRNA levels were upregulated in pancreatic cancers (37). Ryu et al reported that HE4 was not expressed 
A

Suit-2
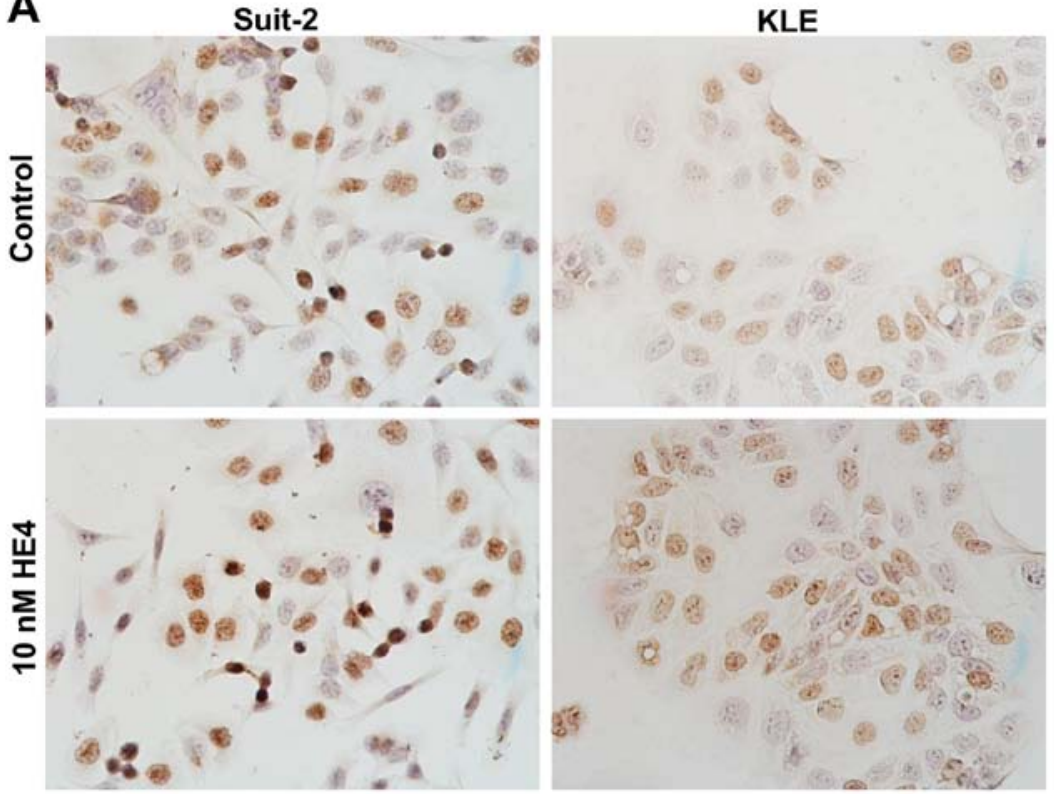

B

C
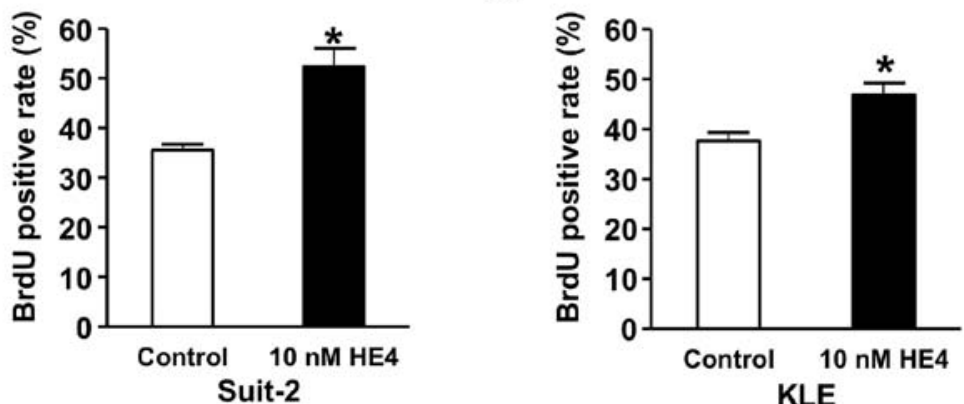

Figure 3. Recombinant HE4 protein promotes DNA synthesis in pancreatic cancer and endometrial cancer cells. (A) Pancreatic cancer Suit-2 and endometrial cancer KLE cells were seeded in two-well chamber slides, and treated with or without $10 \mathrm{nM}$ HE4 protein for 2 days. After BrdU labeling for 2 h, cells were fixed and stained with mouse biotinylated monoclonal anti-BrdU antibody. Assays were performed three times independently and the representative images were presented (magnification, 40x10). (B and C) The BrdU-incorporation rates for Suit-2 and KLE cells, respectively. Data are presented as mean \pm SD. Student's t-test was performed. ${ }^{*} \mathrm{P} \leq 0.05$.

in normal pancreas but highly expressed in pancreatic cancer cells lines including Capan-1, Capan-2, PL45 and AsPc1, as well as primary pancreatic adenocarcinomas (14). Immunostaining of tissue microarray also indicated that HE4 protein was not detectable in normal pancreas $(11,13)$, but there was weak HE4 protein staining in 3 cases, strong HE4 staining in 4 cases, and negative HE4 staining in 1 case out of 8 cases of pancreaticobiliary carcinoma (11). O'Neal et al indicated that HE4 was not expressed in pancreatic intraepithelial neoplasia (PanIN), but $46.8 \%$ of pancreatic adenocarcinomas had HE4 expression (16). In addition, serum levels of HE4 were also upregulated in pancreatic cancer $(15,19,20)$. These data indicated that HE4 could be a candidate diagnosis marker for pancreatic cancers and HE4 may play an important role in pancreatic cancer progression.

Endometrial cancer is the most common gynecologic malignancy in developed countries. Unlike pancreatic cancer, most endometrial cancers are diagnosed at early stages due to the symptom of postmenopausal bleeding. However, $30 \%$ of EC patients are asymptomatic, making the early detection a significant issue for these cases (38). Multiple studies have demonstrated that serum HE4 is a useful tumor biomarker of EC (17,28). HE4 expression levels correlates positively with aggressive phenotype, tumor size and myometrial invasion of EC $(11,18,26,27)$, but inversely with overall EC patients survival $(26,28,29)$. We have reported that in EC cell culture and mouse xenograft model forced overexpression of HE4 resulted in more aggressive phenotypes (31).

In the present study, we demonstrated that the recombinant, exogenous HE4 protein was able to promote cell proliferation in pancreatic and endometrial cancer cell lines (Figs. 1 and 2). Moreover, the addition of recombinant HE4 protein to Suit-2 and KLE cell cultures increased DNA synthesis (Fig. 3) and induced correspondent changes in the expression of cell cycle regulators. This is the first study on the bioactivity of extracellular HE4 in pancreatic cancer cells. Previously, several studies have shown that overexpression of HE4 affected cell proliferation in ovarian and endometrial cancer cell lines $(31,33,39,40)$. While we could not exclude the bioactivity of intracellular $\mathrm{HE} 4$, the new data indicated that extracellular HE4 secreted into culture medium may contribute to the overall HE4 effects observed in previous overexpression models. 

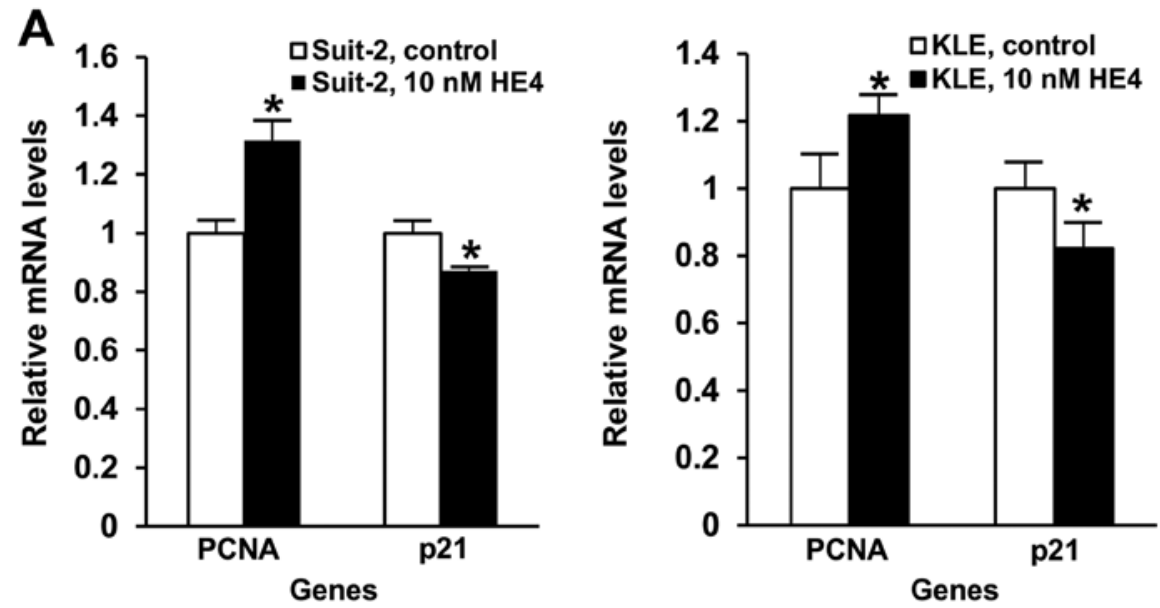

B
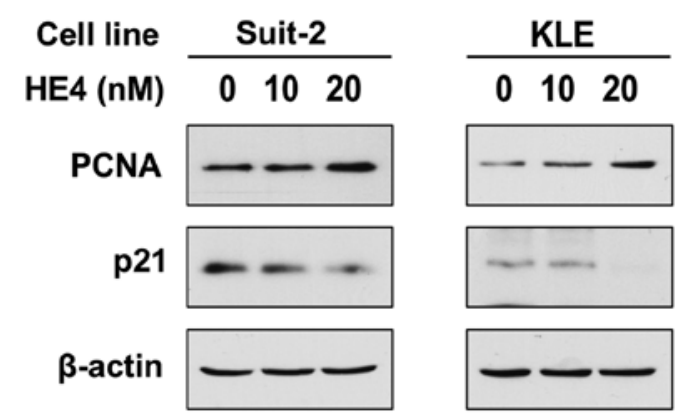

Figure 4. Recombinant HE4 protein regulates PCNA and p21 gene expression in pancreatic cancer and endometrial cancer cells. (A) Relative mRNA levels of PCNA and p21 were measured with real-time PCR after treatment with $10 \mathrm{nM}$ of HE4 or without HE4 for $24 \mathrm{~h}$ in pancreatic cancer Suit-2 (left panel) and endometrial cancer KLE cells (right panel). Results from GAPDH expression were used to standardize the data. Expression levels in control cells were set as 1 and relative expression levels in experimental groups are presented as relative fold-changes. Student's t-test was performed. ${ }^{*} \mathrm{P} \leq 0.05$. (B) Results of western blot analyses. Protein levels of PCNA and p21 were determined with western blot analyses following treatment with 0,10 and $20 \mathrm{nM}$ of $\mathrm{HE} 4$ for $48 \mathrm{~h}$. Assays were performed three times independently and one representative image is presented. $\beta$-actin was used as a protein loading control. Left panel, pancreatic cancer Suit-2 cells. Right panel, endometrial cancer KLE cells.

In cancer patients, HE4 produced by cancer cells is secreted into the extracellular plasma. This raises the possibility that through affecting the surrounding cancer and non-cancer cells HE4 may exerts a paracrine function. Similarly, circulatory HE4 protein released by primary tumor may play an endocrine role by affecting the proliferation of remote cell/tissues, e.g., the metastatic cancer. Thus, our new findings point to a new model of cell-cell interaction mediated by extracellular HE4. The presence and significance of this action in cancer progression need to be examined by specifically designed in vivo experiments.

Our data raise a possibility that extracellular HE4 could affect cell proliferation through directly binding to its receptor or receptor-like proteins on the cell membrane, delivering its stimulatory signals into cytoplasm. For this potential mechanism, HE4 protein remains in the outer space of cell membrane. Although as a $25 \mathrm{kDa}$ glycosylated peptide, HE4 protein could not directly pass through cell membrane, we could not exclude the possibility that through actions like pinocytosis, some HE4 molecules could enter cytoplasm and/or nuclei and thereby exerting its function. In this initial investigation, we did not delineate the detailed mechanism by which recombinant HE4 protein exerts its bioactivity. Nevertheless, the present study provided evidence showing that recombinant HE4 protein could regulate PCNA and p21 gene expression and modulate cell proliferation in pancreatic and endometrial cancer cell lines. As shown in Fig. 4, recombinant HE4 protein increased PCNA expression and decreased p21 expression on both mRNA and protein levels in Suit-2 and KLE cells. PCNA plays important roles in S-phase DNA synthesis and controls establishment of sister chromatid cohesion during S-phase $(41,42)$. p21 binds to cyclin D1-CDK4, cyclin D2-CDK4, cyclin E-CDK2 and cyclin A-CDK2, and inhibits their activities, resulting in an increased phosphorylation of $\mathrm{Rb}(43,44)$. In addition, $\mathrm{p} 21$ controls DNA replication by interaction with PCNA $(45,46)$. These findings indicated that HE4 function may be mediated by $\mathrm{p} 21-\mathrm{CDK}-\mathrm{Rb}$ pathway.

In summary, using the recombinant HE4 protein produced by human cells, we observed that extracellular HE4 is able to promote the proliferation of pancreatic and endometrial cancer cells. By this action, HE4 secreted from cancer cells may carry out paracrine and endocrine functions in cancer patients. The novel HE4 action may have important implications for the progression and metastasis of pancreatic and endometrial cancers. Moreover, extracellular HE4 protein is able to modulate the expression of cell cycle regulators $\mathrm{p} 21$ and PCNA. The exact mechanism by which extracellular HE4 may exert its function in cell cycle regulation remains to be elucidated. 


\section{Acknowledgements}

We thank Dr Kaustubh Datta (University of Nebraska) for providing the pancreatic cancer Suit- 2 cell line. The present study was supported by the Memorial Health University Medical Center/Curtis and Elizabeth Anderson Cancer Institute and Mercer University (ACI/MUSM) Pancreatic Cancer Research Program (Li J.; Jiang S.-W.; and Brower S.); the ACI Excellence through Discovery Laboratory Research Fund (Li J.; Jiang S.-W.; Brower S.; and Glasgow W.); the Distinguished Cancer Scholar Program of Georgia Cancer Coalition (Jiang S.-W.); the National High Technology Research and Development Program of China (863 Program, 2014AA020521 to Wang J.; NSFC 81472450 Li J.); the Research Supplement from Mercer University School of Medicine (Jiang S.-W.); and the Research Start-up fund from Mercer University School of Medicine (Li J.).

\section{References}

1. Siegel R, Ma J, Zou Z and Jemal A: Cancer statistics, 2014. CA Cancer J Clin 64: 9-29, 2014

2. Jemal A, Bray F, Center MM, Ferlay J, Ward E and Forman D: Global cancer statistics. CA Cancer J Clin 61: 69-90, 2011.

3. Ferlay J, Shin HR, Bray F, Forman D, Mathers C and Parkin DM: Estimates of worldwide burden of cancer in 2008: GLOBOCAN 2008. Int J Cancer 127: 2893-2917, 2010.

4. Bardeesy N and DePinho RA: Pancreatic cancer biology and genetics. Nat Rev Cancer 2: 897-909, 2002.

5. Muniraj T, Jamidar PA and Aslanian HR: Pancreatic cancer: A comprehensive review and update. Dis Mon 59: 368-402, 2013.

6. Sakai T, Toguchida J, Ohtani N, Yandell DW, Rapaport JM and Dryja TP: Allele-specific hypermethylation of the retinoblastoma tumor-suppressor gene. Am J Hum Genet 48: 880-888, 1991.

7. Esteller M: CpG island hypermethylation and tumor suppressor genes: A booming present, a brighter future. Oncogene 21: 5427-5440, 2002.

8. Kirchhoff C, Habben I, Ivell R and Krull N: A major human epididymis-specific cDNA encodes a protein with sequence homology to extracellular proteinase inhibitors. Biol Reprod 45: 350-357, 1991.

9. Clauss A, Lilja $\mathrm{H}$ and Lundwall A: A locus on human chromosome 20 contains several genes expressing protease inhibitor domains with homology to whey acidic protein. Biochem J 368: 233-242, 2002.

10. Bingle CD: Towards defining the complement of mammalian WFDC-domain-containing proteins. Biochem Soc Trans 39: 1393-1397, 2011

11. Galgano MT, Hampton GM and Frierson HF Jr: Comprehensive analysis of HE4 expression in normal and malignant human tissues. Mod Pathol 19: 847-853, 2006.

12. Jiang SW, Chen H, Dowdy S, Fu A, Attewell J, Kalogera E, Drapkin R, Podratz K, Broaddus R and Li J: HE4 transcriptionand splice variants-specific expression in endometrial cancer and correlation with patient survival. Int J Mol Sci 14: 22655-22677, 2013.

13. Drapkin R, von Horsten $\mathrm{HH}$, Lin $\mathrm{Y}$, Mok SC, Crum CP, Welch WR and Hecht JL: Human epididymis protein 4 (HE4) is a secreted glycoprotein that is overexpressed by serous and endometrioid ovarian carcinomas. Cancer Res 65: 2162-2169, 2005.

14. Ryu B, Jones J, Blades NJ, Parmigiani G, Hollingsworth MA, Hruban RH and Kern SE: Relationships and differentially expressed genes among pancreatic cancers examined by largescale serial analysis of gene expression. Cancer Res 62: 819-826, 2002.

15. Huang T, Jiang SW, Qin L, Senkowski C, Lyle C, Terry K, Brower S, Chen H, Glasgow W, Wei Y, et al: Expression and diagnostic value of HE4 in pancreatic adenocarcinoma. Int J Mol Sci 16: 2956-2970, 2015.
16. O'Neal RL, Nam KT, LaFleur BJ, Barlow B, Nozaki K, Lee HJ, Kim WH, Yang HK, Shi C, Maitra A, et al: Human epididymis protein 4 is up-regulated in gastric and pancreatic adenocarcinomas. Hum Pathol 44: 734-742, 2013.

17. Angioli R, Miranda A, Aloisi A, Montera R, Capriglione S, De Cicco Nardone C, Terranova C and Plotti F: A critical review on HE4 performance in endometrial cancer: Where are we now? Tumour Biol 35: 881-887, 2014.

18. Moore RG, Miller CM, Brown AK, Robison K, Steinhoff M and Lambert-Messerlian G: Utility of tumor marker HE4 to predict depth of myometrial invasion in endometrioid adenocarcinoma of the uterus. Int J Gynecol Cancer 21: 1185-1190, 2011.

19. Faca VM, Song KS, Wang H, Zhang Q, Krasnoselsky AL, Newcomb LF, Plentz RR, Gurumurthy S, Redston MS, Pitteri SJ, et al: A mouse to human search for plasma proteome changes associated with pancreatic tumor development. PLoS Med 5: e123, 2008.

20. Brand RE, Nolen BM, Zeh HJ, Allen PJ, Eloubeidi MA, Goldberg M, Elton E, Arnoletti JP, Christein JD, Vickers SM, et al: Serum biomarker panels for the detection of pancreatic cancer. Clin Cancer Res 17: 805-816, 2011.

21. Bingle CD and Vyakarnam A: Novel innate immune functions of the whey acidic protein family. Trends Immunol 29: 444-453, 2008.

22. Scott A, Weldon S and Taggart CC: SLPI and elafin: Multifunctional antiproteases of the WFDC family. Biochem Soc Trans 39: 1437-1440, 2011.

23. Chhikara N, Saraswat M, Tomar AK, Dey S, Singh S and Yadav S: Human epididymis protein-4 (HE-4): A novel crossclass protease inhibitor. PLoS One 7: e47672, 2012.

24. LeBleu VS, Teng Y, O'Connell JT, Charytan D, Müller GA, Müller CA, Sugimoto H and Kalluri R: Identification of human epididymis protein-4 as a fibroblast-derived mediator of fibrosis. Nat Med 19: 227-231, 2013

25. Hua L, Liu Y, Zhen S, Wan D, Cao J and Gao X: Expression and biochemical characterization of recombinant human epididymis protein 4. Protein Expr Purif 102: 52-62, 2014.

26. Bignotti E, Ragnoli M, Zanotti L, Calza S, Falchetti M, Lonardi S, Bergamelli S, Bandiera E, Tassi RA, Romani C, et al: Diagnostic and prognostic impact of serum HE4 detection in endometrial carcinoma patients. Br J Cancer 104: 1418-1425, 2011.

27. Kalogera E, Scholler N, Powless C, Weaver A, Drapkin R, Li J, Jiang SW, Podratz K, Urban N and Dowdy SC: Correlation of serum HE4 with tumor size and myometrial invasion in endometrial cancer. Gynecol Oncol 124: 270-275, 2012.

28. Zanotti L, Bignotti E, Calza S, Bandiera E, Ruggeri G, Galli C, Tognon G, Ragnoli M, Romani C, Tassi RA, et al: Human epididymis protein 4 as a serum marker for diagnosis of endometrial carcinoma and prediction of clinical outcome. Clin Chem Lab Med 50: 2189-2198, 2012.

29. Angioli R, Plotti F, Capriglione S, Montera R, Damiani P, Ricciardi R, Aloisi A, Luvero D, Cafà EV, Dugo N, et al: The role of novel biomarker HE4 in endometrial cancer: A case control prospective study. Tumour Biol 34: 571-576, 2013.

30. Lu R, Sun X, Xiao R, Zhou L, Gaoxand Guo L: Human epididymis protein 4 (HE4) plays a key role in ovarian cancer cell adhesion and motility. Biochem Biophys Res Commun 419: 274-280, 2012.

31. Li J, Chen H, Mariani A, Chen D, Klatt E, Podratz K, Drapkin R, Broaddus R, Dowdy S and Jiang SW: HE4 (WFDC2) promotes tumor growth in endometrial cancer cell lines. Int J Mol Sci 14: 6026-6043, 2013.

32. Zhu YF, Gao GL, Tang SB, Zhang ZD and Huang QS: Effect of WFDC 2 silencing on the proliferation, motility and invasion of human serous ovarian cancer cells in vitro. Asian Pac J Trop Med 6: 265-272, 2013.

33. Chen Y, Mu X, Wang S, Zhao L, Wu Y, Li J and Li M: WAP four-disulfide core domain protein 2 mediates the proliferation of human ovarian cancer cells through the regulation of growthand apoptosis-associated genes. Oncol Rep 29: 288-296, 2013.

34. Wang H, Zhu L, Gao J, Hu Z and Lin B: Promotive role of recombinant HE4 protein in proliferation and carboplatin resistance in ovarian cancer cells. Oncol Rep 33: 403-412, 2015.

35. Schmittgen TD and Livak KJ: Analyzing real-time PCR data by the comparative C(T) method. Nat Protoc 3: 1101-1108, 2008.

36. Ahrendt SA and Pitt HA: Surgical management of pancreatic cancer. Oncology 16: 725-743, 2002. 
37. Missiaglia E, Blaveri E, Terris B, Wang YH, Costello E, Neoptolemos JP, Crnogorac-Jurcevic $\mathrm{T}$ and Lemoine NR: Analysis of gene expression in cancer cell lines identifies candidate markers for pancreatic tumorigenesis and metastasis. Int J Cancer 112: 100-112, 2004

38. Hamilton CA, Cheung MK, Osann K, Chen L, Teng NN, Longacre TA, Powell MA, Hendrickson MR, Kapp DS and Chan JK: Uterine papillary serous and clear cell carcinomas predict for poorer survival compared to grade 3 endometrioid corpus cancers. Br J Cancer 94: 642-646, 2006.

39. Zou SL, Chang XH, Ye X, Cheng HY, Cheng YX, Tang ZJ, Zhang ZJ, Gao L, Chen XH and Cui H: Effect of human epididymis protein 4 gene silencing on the malignant phenotype in ovarian cancer. Chin Med J 124: 3133-3140, 2011.

40. Moore RG, Hill EK, Horan T, Yano N, Kim K, MacLaughlan S, Lambert-Messerlian G, Tseng YD, Padbury JF, Miller MC, et al: HE4 (WFDC2) gene overexpression promotes ovarian tumor growth. Sci Rep 4: 3574, 2014.
41. Kelman Z: PCNA: Structure, functions and interactions. Oncogene 14: 629-640, 1997

42. Moldovan GL, Pfander B and Jentsch S: PCNA controls establishment of sister chromatid cohesion during S phase. Mol Cell 23: 723-732, 2006.

43. Harper JW, Adami GR, Wei N, Keyomarsi K and Elledge SJ: The p21 Cdk-interacting protein Cip1 is a potent inhibitor of G1 cyclin-dependent kinases. Cell 75: 805-816, 1993.

44. Xiong Y, Hannon GJ, Zhang H, Casso D, Kobayashi R and Beach D: p21 is a universal inhibitor of cyclin kinases. Nature 366: 701-704, 1993.

45. Waga S, Hannon GJ, Beach D and Stillman B: The p21 inhibitor of cyclin-dependent kinases controls DNA replication by interaction with PCNA. Nature 369: 574-578, 1994.

46. Chen J, Jackson PK, Kirschner MW and Dutta A: Separate domains of p21 involved in the inhibition of Cdk kinase and PCNA. Nature 374: 386-388, 1995. 